UDC 347

LBC 67

\title{
ON RELATIONSHIP BETWEEN THE CONCEPTS OF 'SECURITY' AND 'PROTECTION' OF THE SUBJECTIVE CIVIL RIGHT
}

\author{
Aleksey A. Demin \\ N.I. Lobachevsky Nizhny Novgorod State University, Nizhniy Novgorod, Russian Federation
}

Introduction: the normal functioning of the civil turnover is impossible without free and independent implementation of their subjective rights by the participants of the civil legal relations. This is possible when the law provides not only a mechanism for protecting subjective civil rights, but also a detailed regulated procedure for their implementation. The purpose of this study is to analyze the relationship between the concepts and content of subjective rights and their protection. Methods: the methodological framework for the research is a set of methods of scientific knowledge, among which the main are the historical and comparative law methods, the methods of systematicity and analysis. Results: the paper analyzes the views on the mechanism of acquisition/establishment and implementation of civil rights, as well as the mechanism of protection of subjective civil rights. As a result, the conclusion about the supremacy of the legal mechanism of acquisition/establishment and implementation of subjective civil rights is substantiated. Conclusions: the paper substantiates the approach according to which the implementation of subjective rights should be provided not so much by the mechanism of protection as by the appropriate means of acquisition/establishment and implementation of subjective civil rights. They are fundamental and essential, and the protection mechanism should be "included" as a backup and only if the civil regulation of the processes of acquisition/establishment and implementation of subjective rights will not be able to achieve the desired legal result.

Key words: implementation of civil rights, functions of civil law, subjective right, protection, infringement of the right.

УДК 347

ББК 67.0

\section{О СООТНОШЕНИИ ПОНЯТИЙ «ОБЕСПЕЧЕНИЕ» И «ЗАЩИТА» СУБЪЕКТИВНОГО ГРАЖДАНСКОГО ПРАВА}

\author{
Алексей Александрович Демин \\ Нижегородский государственный университет им. Н.И. Лобачевского, \\ г. Нижний Новгород, Российская Федерация
}

Введение: нормальное функционирование гражданского оборота невозможно без свободного и самостоятельного осуществления участниками гражданских правоотношений принадлежащих им субъективных прав. Такое возможно тогда, когда в законодательстве предусмотрен не только механизм защиты субъективных гражданских прав, но и детально регламентированный порядок их осуществления. Целью настоящего исследования является анализ соотношения понятий и содержания обеспечения субъективных прав и их защиты. Методы: методологическую основу исследования составляют совокупность методов научного познания, среди которых основное место занимают исторический и сравнительно-правовой методы, методы системности и анализа. Результаты: в работе проведен анализ взглядов на механизм приобретения/установлㄹня и осуществления гражданских прав, а также на механизм защиты субъективных гражданских прав. $\AA$ В результате обосновывается вывод о главенстве правового механизма приобретения/установления и осуществления субъективных гражданских прав. Вывод: в работе обосновывается подход, согласно которому осуществление субъективных прав должно обеспечиваться не столько механизмом защиты, сколько надлежащими средствами приобретения/установления и осуществления субъективных гражданских прав. Они являются основными и главными, а механизм защиты должен «включаться» как запасной, и только если 
гражданско-правовое регулирование процессов приобретения/установления и осуществления субъективных прав не сможет обеспечить достижение желаемого правового результата.

Ключевые слова: осуществление гражданских прав, функции гражданского права, субъективное право, защита, нарушение права.

\section{Введение}

Вопросы защиты субъективного гражданского права в последнее время все больше привлекают внимание исследователей. С одной стороны, такой интерес вызван самой необходимостью развития законодательства в этом направлении, поскольку считается, что нормальное развитие гражданских правоотношений и реализация субъективных прав невозможны без обеспечения их надежной защиты. С другой стороны, остается достаточно много спорных вопросов, требующих единообразного подхода к их разрешению.

\section{Подходы к определению термина «защита права»}

Еще в советские годы В.П. Грибанов отмечал, что «в цивилистической науке вопрос о защите гражданских прав с точки зрения принадлежащего управомоченному лицу права на защиту вообще не исследовался. Не прижился в цивилистической науке и практике и сам термин “право на защиту”» [6]. В работах настоящего времени защита права в основном рассматривается как особый механизм правового регулирования, функционирующий с целью обеспечения осуществления субъективного права. Само же субъективное право рассматривается как базис механизма осуществления и защиты субъективного права [1]. Кроме того, о защите прав говорится как о многоцелевом институте, функционирующем с целью не только восстановления нарушенных или оспариваемых прав, но и правоподтверждения [12]. Другими словами, механизм защиты субъективных гражданских прав рассматривается в качестве особого регулятора общественных отношений, что представляется неверным.

В научных работах последних лет можно встретить иной взгляд на механизм осуществления и защиты субъективных гражданских прав. Так, И.А. Еськина отмечает, что «неоднородность гражданско-правового регу- лирования обусловливается наличием дифференцированного законодательного регулирования процессов приобретения, осуществления и защиты гражданских прав. ...Механизм приобретения гражданских прав является основополагающим для механизмов осуществления и защиты гражданских прав... поскольку установление субъективного права обеспечивает беспрепятственное действие механизмов осуществления и защиты прав» [7]. Следовательно, надежное осуществление субъективных гражданских прав должно обеспечиваться не столько механизмом защиты гражданских прав, сколько юридическими механизмами приобретения/установления и осуществления субъективных гражданских прав. И средства названных механизмов являются основными и главными, а механизм защиты должен «включаться» как запасной, и только если гражданско-правовое регулирование процессов приобретения/установления и осуществления субъективных прав не сможет обеспечить достижение желаемого правового результата. Поэтому совершенствование гражданского права должно нацеливаться именно на улучшение правообеспечительного механизма, его средств и инструментов.

Об этом в цивилистической науке косвенно говорят применительно к функциональному предназначению гражданского права. Выделяют регулятивную, охранительную, правозащитную, правовосстановительную [22], карательную, воспитательную, компенсационную функции гражданского права [18]. Тем не менее повсеместно цивилистами признается, что основными функциями гражданского права все же следует считать регулятивную и охранительную функции. И указывается, что регулятивная функция в первую очередь проявляет себя вовне в качестве источника закрепления правил поведения участников гражданского права и направлена на обеспечение тех принципиальных возможностей, которые предусмотрены гражданским законодательством. Охранительная же функция характеризует гражданское право со стороны защиты субъек- 
тивного гражданского права. Эта функция объективно проявляется в качестве фиксатора публично установленных правовых механизмов защиты гражданских прав на случай их нарушения или угрозы нарушения.

Безусловно, каждая из указанных функций выполняет строго определенную задачу, поясняет В.Ф. Яковлев. Он отмечает, что у гражданского права есть две общие функции и они достаточно четко обозначены в ст. 2 ГК РФ. «Первая функция - регулирование отношений и вторая функция - функция защиты. ...Гражданское право определяет правовое положение субъектов: статус, правоспособность, дееспособность. Устанавливаются основания и порядок осуществления права собственности. Определяется порядок регулирования договорно-обязательственных отношений. Определяются основания возникновения и содержание исключительных прав в сфере творческой деятельности. Это все является функцией регулирования. Гражданское право не только регулирует эти отношения, но и защищает их. ...Необходимо все время видеть эту разницу» [23]. Поэтому первостепенной задачей как регулятивной, так и охранительной функции является правовое воздействие на поведение субъектов гражданского права, в связи с этим регулятивная функция является преимущественным направлением воздействия гражданского права на общественные отношения [7].

Гражданское законодательство, определяя основные начала правового регулирования, исходит из того, что участники гражданских правоотношений, являясь юридически равными, действуют своей волей и в своем интереce, беспрепятственно осуществляют права, а в случае их нарушения обеспечивают их защиту (ст. 1, 2 ГК РФ). Опираясь на эти принципиальные положения в науке гражданского права, охранительная функция (функция защиты) стала восприниматься как основная функция, а защита права стала главным условием осуществления субъективных гражданских прав. Так, В.П. Грибанов указывает, что «признавая за тем или иным лицом определенные субъективные права и обязанности, гражданское законодательство предоставляет управомоченному лицу и право на их защиту» [5, с. 104]. И далее говорится о том, что при необеспеченности права от различного рода нарушений средствами защиты право становится «декларативным». Ю.Г. Басин, рассуждая о защите, говорит о ней как о предусмотренной законом системе мер, опирающихся на государственное принуждение и направленных на то, чтобы обеспечить неприкосновенность права и ликвидацию последствий его нарушения [2]. Д.Н. Кархалев указывает, что «для охранительного правоотношения, как показывает анализ гражданского законодательства, характерно то, что реализация права потерпевшего возможна при совершении действий со стороны обязанного субъекта» [11]. А.С. Власова полагает, что «развитие общества, а вместе с ним и законодательства предполагает постепенное совершенствование средств защиты прав. Вместе с тем отсутствие применимого во всех случаях “эффективного механизма защиты” ведет к возможности существования самостоятельных активных действий каждого по защите своих прав не запрещенными законом способами» [4].

Между тем не стоит обращать внимания на высказывание В.П. Грибанова, который подчеркивал, что субъективное право по содержанию представляет собой совокупность ряда возможностей, в том числе осуществлять право своими действиями, требовать определенного поведения. Правомочие же на защиту возникает лишь с нарушением субъективного права либо его оспариванием другими лицами [5, с. 105-106]. Тем самым, правовому регулированию осуществления субъективного гражданского права ученым придавалось первостепенное значение по сравнению с защитой.

Подход к функционированию гражданского права с целью защиты права по меньшей мере ограничивает весь его потенциал. Ведь сам Гражданский кодекс РФ и остальное гражданское законодательство рассматриваются и законодателем, и правоприменителем с точки зрения инструмента защиты нарушенного права, а регулятивные возможности остаются невостребованными. При этом интересы участников гражданских правоотношений, которые должны быть нормативно обеспечены, становятся второстепенными. И с этим нельзя согласиться, так как гражданс- 
кое право всегда служило частным интересам общества и в силу принципа реальности и гарантированности гражданских прав должно рассматриваться как инструмент регулирования нормальных имущественных отношений. На этот счет О.С. Иоффе пишет: «Гражданские права и обязанности в их подавляющей массе связаны с имущественными отношениями. Они обладают, следовательно, определенным материальным, экономическим содержанием. Поэтому такие права должны быть снабжены особыми юридическими гарантиями, обеспечивающими не вообще принудительное, а такое именно их осуществление, которое способно удовлетворить материальные потребности и интересы управомоченного» [10].

Безусловно, следует согласиться с тем, что защита возможна только тогда, когда есть что защищать, и она «осуществима, когда в связи с действиями одного лица у другого лица реально меняется положение и требуются особые средства по его восстановлению в прежнем состоянии» [21, с. 71]. Другими словами: защита требуется только там, где есть нарушение права. Но правонарушения в области гражданско-правового регулирования происходят далеко не всегда. Основная масса обязательственных правоотношений вообще не проходит стадию защиты, поскольку они устанавливаются не с целью их нарушения, а для реального возникновения гражданских прав. Участники таких правоотношений в большей степени заинтересованы в регулировании осуществления их субъективных прав и порядком исполнения обязанностей. Следует согласиться и с тем, что «воплощение социальных потребностей в действительность является осуществлением прав, реализация правовых норм которого происходит через поведение субъектов в полном соответствии с правовыми предписаниями и представляет собой непосредственный результат регулирования» [13]. И поскольку частный интерес воплощается в жизнь через установление и осуществление гражданских прав, то отсюда следует однозначный вывод о том, что первостепенным является детальное правовое регулирование именно порядка осуществления субъективных гражданских прав, а не их защита.
Взять, к примеру, абсолютные правоотношения собственности, где собственник вещи, как правило, заинтересован в законодательном обеспечении беспрепятственного пользования принадлежащей ему вещи. Осуществляя субъективное право на вещь, собственник должен быть обеспечен широкими законными основаниями по использованию собственной вещи, с целью удовлетворения собственного интереса собственника. Объективное право в этом случае должно обеспечивать в первую очередь бездействие других лиц и быть направлено на сохранение вещи. Другим не менее важным примером является необходимость обеспечения осуществления права пользования местами общего пользования (парки, скверы, пляжи и т. п.). Ведь до настоящего времени нет достаточного гражданско-правового регулирования, где определены правовые возможности пользователей (граждан) такими местами.

В относительных правоотношениях правовое регулирование должно быть направлено на обеспечение реализации возможностей, заложенных в обязательственных отношениях. В данном случае такой правовой инструмент, как договор, а также нормы, обеспечивающие возможность участникам договора самостоятельно определять порядок осуществления обязательств (ст. 421 ГК РФ), являются хорошими правовыми средствами, гарантирующими беспрепятственное осуществление субъективных гражданских прав в частных интереcax участников гражданских правоотношений. Поэтому дополнение законодательства нормами, направленными на регулирование нормальных правоотношений, не связанных с нарушениями, может только поддерживаться.

В последнее время наблюдаются отдельные изменения в гражданско-правовом регулировании в этом направлении. Так, например, ГК РФ дополнен нормой, где рассматривается возможность при осуществлении предпринимательской деятельности соглашением предусмотреть обязанность одной стороны возместить имущественные потери другой стороны, возникшие в случае наступления определенных в таком соглашении последствий (ст. 406.1 ГК РФ). Или обеспечение нормального осуществления гражданских прав и обязанностей осуществляется за счет 
обеспечительного платежа (ст. 381.1 ГК РФ). Кроме того, в практике широко распространены случаи установления штрафа за односторонний отказ от договора, если такой штраф предусмотрен самим договором [15].

Безусловно, осуществление субъективного гражданского права без обеспечения его надежными правовыми средствами защиты может сделать бессмысленным даже самое детальное правовое регулирование, ведь не исключено, что осуществление субъективного права может не приносить каких-либо ожидаемых правовых результатов управомоченному лицу. В таком случае без правовых средств защиты не обойтись. Однако все же первостепенной задачей видится разработка и закрепление правовых средств осуществления субъективного гражданского права. На этот счет Н.В. Полякова отмечает, что «без установления субъективного гражданского права в рамках того или иного правоотношения невозможно регулирование общественных отношений, так как поведение лиц, действующих на той или иной стороне гражданского правоотношения, может быть упорядочено только посредством приобретения субъективных прав или установления гражданско-правовых обязанностей» [17]. В противном случае, фокусируя усилия на развитии правовых средств и механизма защиты, при этом опуская регулятивную функцию гражданского права, можно столкнуться с хорошей обеспеченностью правовой защиты субъективного права, нормальное осуществление которого невозможно.

Кроме того, нужно учитывать, что само понятие «защита» связано с реакцией лица, чьи права нарушены вследствие совершенного правонарушения, либо имеется угроза нарушения субъективных гражданских прав. Так, ст. 11 ГК РФ указывает на защиту нарушенных или оспоренных гражданских прав, реализуемую в соответствии с подведомственностью дел, установленной процессуальным законодательством. В ст. 12 ГК РФ установлены способы защиты, которые защищающееся лицо применяет непосредственно до нарушения либо после нарушения с целью восстановления права или компенсации на случай невозможности восстановления нарушенного права. Далее предусмат- ривается также и самозащита права, которая имеет те же основания для защиты, что и защита права в судебном или административном порядке. Тем самым, термин «защита» связан с совершенным или готовящимся правонарушением гражданских прав. Отсюда следует и особый механизм со свойственными ему правовыми средствами, обеспечивающими осуществление защиты нарушенного права либо ликвидацию угрозы правонарушения.

Таким образом, каждая из функций гражданского права реализуется за счет установления особых правовых средств в законе. Этот вывод является прикладным, поскольку каждый раз, применяя норму, необходимо убеждаться в ее функциональном предназначении. Согласимся и с тем, что это важно и при законотворческом процессе, поскольку «при создании конкретной нормы права легче определить, отвечает ли она функциональному назначению отрасли права (или института права), в состав которой предполагается ее включение» [18]. Следовательно, принимаемые законодателем правовые акты должны иметь в своем содержании именно те правовые средства, которые обусловлены их принятием. К примеру, Федеральный закон «О защите прав юридических лиц и индивидуальных предпринимателей при осуществлении государственного контроля (надзора) и муниципального контроля» [20] направлен на недопушение нарушения предпринимателей при проведении проверочных действий в отношении предпринимателей. Соответственно, перед законодателем должна стоять цель детального закрепления правовых средств защиты прав субъектов предпринимательства. В свою очередь, представляется, что Закон «О защите прав потребителей» [8] должен быть в первую очередь ориентирован на обеспечение осуществления прав потребителей при реализации своих гражданских прав и интересов в ходе приобретения товаров, работ или услуг, а не на защиту в качестве основного средства осуществления прав потребителей.

Аналогичный вывод прослеживается и в судебной практике. Так, Верховный суд РФ указал, что Закон «О защите прав потребителей» регулирует отношения, возникающие между потребителями и изготовителями, ис- 
полнителями, импортерами, продавцами при продаже товаров (выполнении работ, оказании услуг), устанавливает права потребителей на приобретение товаров (работ, услуг) надлежащего качества и безопасных для жизни, здоровья, имущества потребителей и окружающей среды, получение информации о товарах (работах, услугах) и об их изготовителях (исполнителях, продавцах), просвещение, государственную и общественную защиту их интересов, а также определяет механизм реализации этих прав [16].

Такой вывод сделан в связи с возникшим спором между автосалоном - продавцом автомобиля и его покупателем относительно передачи паспорта транспортного средства покупателю после заключения договора купли-продажи. В частности, Верховный суд РФ указывает, что в соответствии со ст. 464 ГК РФ, если продавец не передает или отказывается передать покупателю относящиеся к товару принадлежности или документы, которые он должен передать в соответствии с законом, иными правовыми актами или договором купли-продажи (п. 2 ст. 456), покупатель вправе назначить ему разумный срок для их передачи. В случае, когда принадлежности или документы, относящиеся к товару, не переданы продавцом в указанный срок, покупатель вправе отказаться от товара, если иное не предусмотрено договором. Далее суд указывает, что приведенная правовая норма предоставляет покупателю право при соблюдении указанных в ней условий отказаться от товара при ненадлежащем исполнении продавцом обязанности по передаче покупателю относящихся к товару документов, но не предусматривает каких-либо мер гражданскоправовой ответственности, подлежащих применению к продавцу в случае причинения покупателю убытков данными действиями [14]. Тем самым, Верховный суд РФ на этом примере обратил внимание на функциональное предназначение норм и разграничил их применение в зависимости от выполняемых ими задач.

\section{Выводы}

Стабильность гражданского оборота в первую очередь зависит от разработанности правовых средств, обеспечивающих свободное и беспрепятственное осуществление гражданских прав, а также от эффективного механизма установления или приобретения гражданских прав. Именно направленность на обеспечение поведенческих возможностей правообладателей делает гражданское право надежным инструментом осуществления субъективных прав и средством воплощения в жизнь таких важных принципов, как реальность и гарантированность осуществления гражданских прав.

\section{СПИСОК ЛИТЕРАТУРЫ}

1. Андреев, Ю. Н. Механизм гражданско-правовой защиты / Ю. Н. Андреев. - М. : Норма : Инфpa-M, 2010.-464 c.

2. Басин, Ю. Г. Основы гражданского законодательства о защите субъективных гражданских прав / Ю. Г. Басин // Проблемы применения Основ гражданского законодательства и Основ гражданского судопроизводства Союза ССР и союзных республик : сб. материалов. - Саратов, 1971. - С. 32-37.

3. Вавилин, Е. В. Осуществление и защита гражданских прав / Е. В. Вавилин / РАН ; Ин-т государства и права. - М. : Волтерс Клувер, 2009. - 338 с.

4. Власова, А. С. Самозащита в корпоративных правоотношениях / А. С. Власова // Гражданское право. - 2016. - № 1. - С. 17-20.

5. Грибанов, В. П. Осуществление и защита гражданских прав / В. П. Грибанов. - М. : Статут, 2001. $-411 \mathrm{c}$.

6. Грибанов, В. П. Пределы осуществления и защиты гражданских прав / В. П. Грибанов. - М. : Статут, 2000.- 105 с.

7. Еськина, И. А. Механизм приобретения гражданских прав : автореф. дис. ... канд. юрид. наук / Еськина Ирина Александровна. - Н. Новгород, 2015. $-29 \mathrm{c}$.

8. Закон РФ от 07.02.1992 № 2300-1 «О защите прав потребителей». - Электрон. текстовые дан. Режим доступа: http:/www.consultant.ru/document/ cons_doc_LAW_305/(дата обращения: 18.02.2018).Загл. с экрана.

9. Ибрагимова, С. В. Регулятивная функция гражданского права / С. В. Ибрагимова // Вестник Пермского университета. Юридические науки. 2016. - № 4. - С. 413-417.

10. Иоффе, О. С. Избранные труды: Советское гражданское право / О. С. Иоффе. - СПб. : Юрид. центр «Пресс», 2004. - 40 с.

11. Кархалев, Д. Н. Охранительное правоотношение / Д. Н. Корхалев. - М. : Статут, 2009. - 27 с. 
12. Кузнецова, Н. С. Защита субъективных гражданских прав и гражданско-правовая ответственность: вопросы соотношения / Н. С. Кузнецова // Защита гражданских прав: Избранные аспекты : сб. ст. -М. : Статут, 2017. - С. 91-103.

13. Малеин, Н. С. Юридическая ответственность и справедливость / Н. С. Малеин. - М. : Манускрипт, 1992. - 204 с.

14. Обзор судебной практики Верховного суда Российской Федерации № 4 (2017). - Электрон. текстовые дан. - Режим доступа: http://www.consultant. ru/document/cons_doc_LAW_282851/ (дата обращения: 28.02.2018). - Загл. с экрана.

15. Определение Верховного суда РФ от 03.11.2015 № 305-ЭС15-6784 по делу № А40-53452/ 2014. - Электрон. текстовые дан. - Режим доступа: http://www.consultant.ru/cons/cgi/online.cgi?req= doc;base=ARB;n=442651\#017646516549750424 (дата обращения: 28.02.2018). - Загл. с экрана.

16. Определение Верховного суда РФ от 10.01.2017 № 41-КГ16-44. - Электрон. текстовые дан. - Режим доступа: http://www.consultant.ru/ cons/cgi/online.cgi?req $=$ doc; base $=A R B ; n=489029 \#$ 003625410384158756 (дата обращения: 18.02.2018). Загл. с экрана.

17. Полякова, Н. В. Субъективное гражданское право и механизм его осуществления / Н. В. Полякова // Журнал ДНК Права. - 2014. - № 4. - С. 32-34.

18. Рыженков, А. Я. Компенсационная функция в гражданском праве / А. Я. Рыженков. - Саратов : Изд-во Сарат. ун-та, 1983. - С. 8-28.

19. Рыженков, А. Я. Функции гражданского права: вопросы теории / А. Я. Рыженков // Пробелы в российском законодательстве. - 2012. - № 4. С. $44-49$.

20. Федеральный закон от 26.12.2008 № 294-Ф3 «О защите прав юридических лиц и индивидуальных предпринимателей при осуществлении государственного контроля (надзора) и муниципального контроля». - Электрон. текстовые дан. - Режим доступа: http://www.consultant.ru/document/cons doc_LAW_83079/(дата обращения: 18.02.2018). Загл. с экрана.

21. Чеговадзе, Т. А. Основания для применения гражданско-правовой защиты / Т. А. Чеговадзе // О проблемах совершенствования российской правовой системы : материалы IX Междунар. науч.практ. конф. / под ред. проф. Л. А. Чеговадзе. Н. Новгород : АНО «НОЦ “ЦЕЗИУС”», 2015.

22. Яковлев, В. Ф. Гражданско-правовые средства обеспечения интересов личности в договорных отношениях / В. Ф. Яковлев // Гражданско-правовая охрана интересов личности в СССР : межвуз. сб. науч. тр. - Свердловск, 1977. - Вып. 53. - С. 37-40.

23. Яковлев, В. Ф. Избранные труды / В. Ф. Яковлев. - М. : Статуг, 2012. - 351 c.

\section{REFERENCES}

1. Andreev Yu.N. Mekhanizm grazhdanskopravovoy zashchity [Civil Protection Mechanism]. Moscow, Norma; Infra-M Publ., 2010. 464 p.

2. Basin Yu.G. Osnovy grazhdanskogo zakonodatelstva o zashchite subyektivnykh grazhdanskikh prav [Fundamentals of Civil Legislation and Protection of Subjective Civil Rights]. Problemy primeneniya Osnov grazhdanskogo zakonodatelstva $i$ Osnov grazhdanskogo sudoproizvodstva Soyuza SSR $i$ soyuznykh respublik: sb. materialov [Problems of Applying the Fundamentals of Civil Law and the Principles of Civil Procedure of the USSR and Union Republics: Collected Materials]. Saratov, 1971, pp. 32-37.

3. Vavilin E.V. Osushchestvlenie $i$ zashchita grazhdanskikh prav [Implementation and Protection of Civil Rights]. Moscow Volters Kluver Publ., 2009. 338 p.

4. Vlasova A.S. Samozashchita v korporativnykh pravootnosheniyakh [Self-Protection in Corporate Legal Relations]. Grazhdanskoe pravo [Civil Law], 2016, no. 1, pp. 17-20.

5. Gribanov V.P. Osushchestvlenie i zashchita grazhdanskih prav [Implementation and Protection of Civil Rights]. Moscow Statut Publ., 2001. 411 p.

6. Gribanov V.P. Predely osushchestvleniya $i$ zashchity grazhdanskikh prav [Limits of the Exercise and Protection of Civil Rights]. Moscow, Statut Publ., 2000. 105 p.

7. Eskina I.A. Mekhanizm priobreteniya grazhdanskikh prav: avtoref. dis. ... kand. yurid. nauk [The Mechanism of Civil Rights Acquisition. Cand. jurid. sci. abs. diss.]. Nizhny Novgorod, 2015. 29 p.

8. Zakon RF ot 07.02.1992 № 2300-1 "O zashchite prav potrebiteley» [Law of the Russian Federation of February 7, 1992 no. 2300-1 'On Protection of Consumer Rights']. URL: http://www. consultant.ru/document/cons_doc_LAW_305/. (accessed 18 February 2018).

9. Ibragimova S.V. Regulyativnaya funktsiya grazhdanskogo prava [Regulatory Function of Civil Law]. Vestnik Permskogo universiteta. Yuridicheskie nauki, 2016, no. 4, pp. 413-417.

10. Ioffe O.S. Izbrannye trudy: Sovetskoe grazhdanskoe pravo [Selected Works: the Soviet Civil Law]. Saint Petersburg, Yuridicheskiy tsentr Press, 2004. 40 p.

11. Karkhalev D.N. Okhranitelnoe pravootnoshenie [Protective Legal Relation]. Moscow, Statut Publ., 2009. 27 p.

12. Kuznetsova N.S. Zashchita subyektivnykh grazhdanskikh prav i grazhdansko-pravovaya otvetstvennost: voprosy sootnosheniya [Protection of Subjective Civil Rights and Civil Liability: Issues of Correlation]. Zashchita grazhdanskikh prav: Izbrannye aspekty: sb. st. [Civil Rights Protection: 
Selected Aspects. Collected Articles]. Moscow Statut Publ., 2017. pp. 91-103.

13. Malein N.S. Yuridicheskaya otvetstvennost $i$ spravedlivost [Legal Responsibility and Justice]. Moscow, Manuskript Publ., 1992. 204 p.

14. Obzor sudebnoy praktiki Verkhovnogo suda Rossiyskoy Federatsii [Review of Judicial Practice of the Supreme Court of the Russian Federation], 2017, no. 4. URL: http://www.consultant.ru/document/ cons_doc_LAW_282851/. (accessed 28 February 2018).

15. Opredelenie Verkhovnogo suda RF ot 03.11.2015 № 305-ES15-6784 po delu № A40-53452/ 2014 [Decision of the Supreme Court of November 3, 2015 No. 305-ES15-6784 on Case no. A40-53452/2014]. URL: http://www.consultant.ru/cons/cgi/online.cgi? req $=$ doc; base $=A R B ; n=442651 \# 017646516549750424$. (accessed 28 February 2018).

16. Opredelenie Verkhovnogo suda RF ot 10.01.2017 № 41-KG16-44 [Decision of the Supreme Court of the Russian Federation of January 10, 2017 no. 41-KG16-44]. URL: http://www.consultant.ru/cons/ cgi/online.cgi?req $=$ doc; base $=A R B ; n=489029 \#$ 003625410384158756. (accessed 18 February 2018).

17. Polyakova N.V. Subektivnoe grazhdanskoe pravo i mekhanizm ego osushchestvleniya [Subjective Civil Law and the Mechanism of Its Implementation]. Zhurnal DNK Prava, 2014, no. 4, pp. 32-34.

18. Ryzhenkov A.Ya. Kompensatsionnaya funktsiya $v$ grazhdanskom prave [Compensation Function in the Civil Law]. Saratov, Izd-vo Sarat. un-ta, 1983, pp. 8-28.

19. Ryzhenkov A.Ya. Funktsii grazhdanskogo prava: voprosy teorii [Functions of Civil Law:
Theoretical Issues]. Probely $v$ rossiyskom zakonodatelstve, 2012, no. 4, pp. 44-49.

20. Federalnyy zakon ot 26.12.2008 № 294-FZ «O zashchite prav yuridicheskikh lits $i$ individualnykh predprinimateley pri osushchestvlenii gosudarstvennogo kontrolya (nadzora) i munitsipalnogo kontrolya» [Federal Law of December 26, 2008 No. 294-FL 'On the Protection of the Rights of Legal Entities and Individual Entrepreneurs in the Exercise of State Control (Supervision) and Municipal Control']. URL: http:// www.consultant.ru/document/cons_doc_LAW_ 83079/. (accessed 18 February 2018).

21. Chegovadze T.A. Osnovaniya dlya primeneniya grazhdansko-pravovoy zashchity [Grounds for Civil Legal Protection]. Chegovadze L.A., ed. O problemakh sovershenstvovaniya rossiyskoy pravovoy sistemy: materialy IX Mezhdunar. nauch.prakt. konf. [On the Improvement of Russian Legal System: Proceedings of the $9^{\text {th }}$ International Research and Practice Conference]. Nizhny Novgorod, TsEZIUS Publ., 2015.

22. Yakovlev V.F. Grazhdansko-pravovye sredstva obespecheniya interesov lichnosti $\mathrm{V}$ dogovornykh otnosheniyakh [Civil-legal means of ensuring the interests of the individual in contractual relations]. Grazhdansko-pravovaya okhrana interesov lichnosti v SSSR: mezhvuz. sb. nauch. tr. [Civil and Legal Protection of Personal Interests in the USSR: Interuniversity Collection of Academic Papers]. Sverdlovsk, 1977, iss. 53, pp. 37-40.

23. Yakovlev V.F. Izbrannye trudy [Selected Works]. Moscow, Statut Publ., 2012. 351 p.

\section{Information about the Author}

Aleksey A. Demin, Candidate of Sciences (Jurisprudence), Associate Professor, Department of Civil Law and Procedure, N.I. Lobachevsky Nizhny Novgorod State University, Prosp. Gagarina, 23, 603950 Nizhniy Novgorod, Russian Federation, bullpit@rambler.ru.

\section{Информация об авторе}

Алексей Александрович Демин, кандидат юридических наук, доцент кафедры гражданского права и процесса, Нижегородский государственный университет им. Н.И. Лобачевского, просп. Гагарина, 23, 603950 Нижний Новгород, Российская Федерация, bullpit@rambler.ru. 